Boise State University

ScholarWorks

Management Faculty Publications and

Presentations

Department of Management

8-2018

\title{
Political Skill and Will as Predictors of Impression Management Frequency and Style: A Three-Study Investigation
}

\author{
Liam P. Maher \\ Boise State University \\ Vickie Coleman Gallagher \\ Cleveland State University \\ Ana Maria Rossi \\ Clinica de Stress e Biofeedback \\ Gerald R. Ferris \\ Florida State University
}

\section{Publication Information}

Maher, Liam P.; Coleman Gallagher, Vickie; Rossi, Ana Maria; and Ferris, Gerald R. (2018). "Political Skill and Will as Predictors of Impression Management Frequency and Style: A Three-Study Investigation". Journal of Vocational Behavior, 107, 276-294. https://doi.org/10.1016/j.jvb.2018.05.004

This is an author-produced, peer-reviewed version of this article. (c) 2018, Elsevier. Licensed under the Creative Commons Attribution-NonCommercial-No Derivatives license]. The final, definitive version of this document can be found online at The Journal of Vocational Behavior, doi: 10.1016/j.jvb.2018.05.004 


\section{Political Skill and Will as Predictors of Impression Management Frequency and Style: A Three-Study Investigation}

Theoretical and empirical research on political skill has increased considerably over the past 15 years. These findings have been consistent with the theoretical framework provided by Ferris, Treadway, Perrewé, Brouer, Douglas, and Lux (2007), and extended by Munyon, Summers, Thompson, and Ferris (2015), stating that political skill equips individuals with a resource that provides them an advantage with regard to social effectiveness and goal attainment. These advantages manifest themselves through superior intrapsychic (e.g., stress management), behavioral (e.g., performance), and interpersonal (e.g., impression management execution) processes.

Despite the significant progress that scholars have made investigating the effects of political skill in organizations, far less inquiry has focused on the fraternal construct of political skill, namely, political will. Mintzberg (1983) coined the concepts of political skill (along with Pfeffer, 1981) and political will, a construct largely considered to be the motivational component of the political perspectives on organizations (Treadway, 2012). Mintzberg theorized that organizational actors require requisite amounts of both ability (i.e., political skill) and motivation (i.e., political will) to succeed in navigating their environments. Yet, the vast body of organizational politics literature that examines the effects of political skill has ignored the role of political will, which is the other half of the theoretical frame by which Mintzberg proposed that individuals succeed in organizations.

A great deal of organizational and societal change occurs as the result of effective political behavior, and these outcomes are achieved when leaders and other individuals are motivated to engage in goal-directed behaviors that achieve personal and organizational 
objectives (Kapoutsis, Papalexandris, Treadway, \& Bentley, in press). Political skill can theoretically lay dormant and unutilized within an unmotivated individual, and thus measuring the motivational component of political behavior is necessary when evaluating outcomes. Recent theoretical expansion (Treadway, 2012) and construct elaboration and validation (Kapoutsis et al., in press) has provided the opportunity for organizational scholars to examine the effects of these constructs in tandem, as Mintzberg intended over three decades ago.

Scholars have theorized that the motivation to act in a political manner (i.e., political will), and the ability to select proper political strategies, and then successfully implement these strategies (i.e., political skill) leads to effective individual- and/or organizational-goal attainment (through successful political behavior) (Treadway, Hochwarter, Kacmar, \& Ferris, 2005). To date, research primarily has focused on the outward interpersonal execution of political strategies, whereas empirically examining how political skill and will contribute to individuals' selection of impression management strategies has yet to be fully explored, despite its recognized importance (Ferris et al., 2007; Munyon et al., 2015). Specifically, many studies have examined the interpersonal processes that allow impression management strategies to be outwardly effective at influencing different audiences (Treadway, Ferris, Duke, Adams, \& Thatcher, 2007). However, despite the need to investigate the antecedents of different impression management strategies (Bolino, Long, \& Turnley, 2015), little work has been done to explore the role that political skill and political will play in strategically selecting impression management strategies.

These omissions are unfortunate, as they leave the field of organizational politics without an understanding of why and how political strategies are selected. Furthermore, it leaves the field without empirical evidence that supports some of the basic notions of political skill and political will, which are foundational constructs in the field, with important theoretical implications 
(Harris, Maher, \& Ferris, 2016; Munyon et al., 2015; Treadway, 2012; Treadway et al., 2005). Indeed, this gap in our understanding of politics in organizations seriously limits significant progress being made with regard to theory and research in this area.

The present multi-study, multi-sample investigation seeks to fill these gaps, and contribute to the field by achieving three objectives. First, using three studies and four diverse samples of employees, this investigation seeks to replicate the different impression management configurations identified by Bolino and Turnley (2003). Second, the present research seeks to demonstrate that political skill is a personal resource that aids in the process of strategic selection and avoidance of particular impression management tactic configurations (i.e., thus validating and expanding the theoretical notions proposed by Ferris et al. 2007 and Munyon et al., 2015).

Third, our investigation aims to establish political will as a theoretically vital antecedent of impression management configurations. We draw from the theoretical propositions of Harris and colleagues (2016), which are grounded in the too-much-of-a-good-thing effect (Pierce \& Aguinis), to investigate whether optimal levels of political will are present in individuals who are attempting to create and manage positive impressions of others. Indeed, those who use low and high levels of impression management are not viewed as positively as those who are able to strike a balance (Bolino \& Turnley, 2003). Finally, the methodology we utilize employs cluster analysis to promote a configurational approach to impression management use, which is an important technique to conceptually organize complex multi-dimensional organizational phenomena (Ketchen \& Shook, 1996), and is a notably underused technique in exploring behavioral phenomena in the workplace (Short, Payne, \& Ketchen, 2008). 
This investigation draws upon the two-component theoretical model of impression management selection developed by Leary and Kowalski (1990) to explain the role of political skill and political will in the selection of different configurations of impression management strategies (Bolino \& Turnley, 2003). In the following sections, we briefly review the literature on impression management, explain the tenets of Leary and Kowalski’s two-component model, differentiate between configurations and individual tactics, and describe the theoretical justification for our hypotheses.

\section{Impression Management}

Nature of impression management. Individuals concern themselves with the images that others hold of them, as impression management processes allow individuals to conform to social norms, avoid blame or gain credit, maintain or enhance their self-concept, and strategically wield power and social influence (Tedeschi, 2013). Formally defined, impression management in organizations represents interactive behaviors that individuals employ to create, maintain, or manipulate the images that others hold of them (Bolino et al., 2015). The importance of impression management in organizations has been illustrated by the myriad studies that have examined the tactical advantages and disadvantages of impression management in diverse work settings. Indeed, successfully managing impressions of others in the workplace is a vital aspect of getting hired into an organization, establishing a strong reputation (Diekmann, Blickle, Hafner, \& Peters, 2015), getting promoted (Blickle et al., 2011), and effectively navigating the work environment for personal and organizational gain (Bolino et al., 2015).

Although impression management behaviors often occur as a result of strategic and premeditated thought, these behaviors also can be habitual or unconscious (Leary \& Kowalski, 1990), such as ingratiatory behavior that is normative in nature, given the social context. 
However, the preponderance of scholarly inquiry, and certainly within the organizational politics literature, has focused on examining the effects of impression management behaviors that are strategic and either consciously executed or habitually absorbed into individuals' routinized behavior within their organization. Actors direct these behaviors towards premediated targets in order to create or maintain an image of themselves in an attempt to increase their social capital (Baron \& Markman, 2000), and gain career-enhancing sponsorship or resources (Wayne \& Liden, 1995). This is not to say that all strategic impression management behaviors are deceitful in nature, as actors may attempt to create or maintain images of themselves that are consistent with their own self-concept (Rosenfeld, 1997), or with objective assessments of reality.

Additionally, regardless of the true authenticity of the attempt, like most political behaviors (Treadway, 2012), impression management behaviors inherently involve risk (Liden \& Mitchell, 1988). Being suspected of, or caught using, an impression management tactic that is merely perceived by the target as disingenuous or deceitful produces a counterproductive effect, as some social contexts are not conducive to impression management attempts (Liden \& Mitchell, 1988), or targets may sense the manipulative nature of the behavior (Treadway et al., 2007).

Thus, individuals need to be attuned to the risks involved in engaging in impression management behavior, and monitor the frequency of their tactics as well as the type of impressions that they form. Although a great deal of research has examined the effectiveness and consequences of impression management, it is just as important that we understand impression management's behavioral and cognitive antecedents (e.g., Barsness, Diekmann, \& Seidel, 2005; Bourdage, Wiltshire, \& Lee, 2015). Clearly, more research is needed to fully understand why 
and how people choose to engage in different patterns, profiles, or configurations of impression management behaviors (Bolino et al., 2015).

Antecedents and classifications of impression management. Leary and Kowalski (1990) developed a two-component model that we utilize as the theoretical foundation of this investigation. They proposed that impression management is comprised of two discrete processes: Impression motivation and impression construction. Impression motivation is the degree to which people are motivated to control how other individuals view them, and this is a function of the goal-relevance of the desired image, the value of the outcome of the goal, and the discrepancy between perceptions of the current and desired images.

Impression construction involves choosing the type of impression to create, and the precise tactics and strategies to be used to create these images. The cognitive determinants of impression construction are the self-concept of the individual, the perceptions of the contextspecific desirability or undesirability of different identity images, the perceptions of role constraints, the perceived values of their targets, and their perception of their current or potential social image (Leary \& Kowalski, 1990).

The literature on impression management has utilized several different taxonomies of strategic impression management behavior (e.g., Tedeschi \& Melburg, 1984). However, the most widely used taxonomy is that of Jones and Pittman (1982), which is comprised of exemplification, ingratiation, self-promotion (which are positive impression management tactics), intimidation, and supplication (which are negative impression management tactics) (Bolino \& Turnley, 1999). Exemplification is an attempt to appear dedicated by going above and beyond the call of duty. Ingratiation is the use of flattery or doing favors for others in order to be viewed as likeable. Self-promotion involves the use of self-directed compliments in order 
to make the target view the self as competent. Supplication advertises the misgivings or shortcomings of an individual in an attempt to appear needy. Lastly, intimidation is used in order to be viewed as dangerous, coercive, or threatening.

\section{Configurations vs. Tactics of Influence}

Multidimensional constructs can be conceptualized in three different ways (Law, Wong, \& Mobley, 1998). First, latent models are comprised of lower-level constructs that comprise the higher-level construct, and high scores across all dimensions indicate a high level of this deeper, unifying impression management construct. Second, an aggregate model relies on an algebraic function that determines the relative contribution of the underlying dimensions to the higherorder construct. Third, a profile model consists of different patterns or configurations of the underlying dimensions.

Prior research has found that latent and aggregate models of impression management are not appropriate, as, although some individuals may choose to uniformly employ all five impression management tactics at varying levels, it is far more likely that tactics are used in combination, and that patterns in these combinations will emerge (Bolino \& Turnley, 2003). Similar patterns also were found in the related but distinct fields of research on influence tactics, as subjects were found to use the tactics at high (shotgun), low (bystander), or situationally calibrated (tactician) levels of use (Farmer \& Maslyn, 1999; Kipnis \& Schmidt, 1984). This is conceptually similar to the aggressives, passives, and positives patterns found in impression management tactics research by Bolino and Turnley.

Simply aggregating scores across impression management tactics would oversimplify the use of these tactics, and would not allow scholars to investigate the nuances of impression management strategies. Because we seek to investigate whether individuals with political skill 
and political will do indeed employ nuanced, targeted, and discriminating impression management strategies, the illumination of these patterns is of particular importance, and thus, we investigate impression management using a configuration, pattern, or profile model. This design is a marked departure from the few other scholarly investigations to consider political skill as an antecedent of impression management tactics (e.g., Brouer, Badawy, Gallagher, \& Habler, 2015).

Bolino and Turnley (2003) found support for three different configurations of impression management tactic selection: Aggressives, passives, and positives. Aggressives used all five impression management strategies indiscriminately at relatively high levels of frequency. Passives used all five impression management strategies at relatively low levels of frequency. Positives used the positive tactics (i.e., exemplification, ingratiation, and self-promotion) at relatively high levels of frequency, but used negative tactics (i.e., intimidation and supplication) at relatively low levels of frequency, and coworker reports revealed that positives were the most desirable workgroup members. Furthermore, individual difference variables were shown to be associated with different strategies. Specifically, self-monitoring was associated with positives and Machiavellianism was associated with aggressives.

The first contribution of the present investigation is to constructively replicate the configurational findings of Bolino and Turnley (2003) in several diverse samples, using the five different impression management tactics and three targets (i.e., peers, subordinates/support staff, and supervisors). Thus, we hypothesize that:

Hypothesis 1a: A three-cluster configuration of impression management tactics is the most appropriate cluster solution. 
Hypothesis $1 b$ : The three clusters of impression management tactics are consistent with previous theory such that the tactics will be grouped into aggressives, passives, and positives.

Political skill. The theoretical and empirical connections of political skill to impression management have been explored since the nascent stages of the construct's development (e.g. Ferris et al., 2007). Political skill is formally defined as "the ability to effectively understand others at work, and to use such knowledge to influence others to act in ways that enhance one's personal and/or organizational objectives," and is comprised of the dimensions: social astuteness, interpersonal influence, networking ability, and apparent sincerity (Ferris et al., 2005, p. 127). Social astuteness is the ability to properly recognize and diagnose cues from the social environment. Interpersonal influence is the ability to use a subtle but convincing style to influence the attitudes and behaviors of others and utilize influence tactics appropriate for the situation. Networking ability is the ability to properly assess the interpersonal networks of an organization, and then position one's self in a strategically advantageous position within that network. Apparent sincerity is the ability to interact with others in a way that is perceived as genuine and authentic.

Theory in this area posits that political skill is a personal resource that can lead to greater individual performance (Bing et al., 2011; Blickle et al., 2008; Munyon et al., 2013). Political skill is a function of three processes: Intrapsychic processes, behavioral processes, and interpersonal processes (Ferris et al., 2007; Munyon et al., 2015). To date, the vast majority of literature on political skill and impression management has focused on interpersonal processes that result in politically skilled individuals successfully executing impression management tactics toward others (Treadway et al., 2007). However, the intrapsychic and behavioral processes that 
allow politically skilled individuals to properly select the appropriate impression management tactics has received little scholarly attention.

To date, only Brouer and colleagues (2015) have examined the selection of tactics, as they found support that certain dimensions of political skill (i.e., social astuteness and networking ability) were positively associated with the selection of positive impression management tactics directed at one’s manager. Specifically, this research highlighted the intrapsychic nature of positive tactic choice when persons are well networked and socially astute. However, their investigation examined positive (i.e., exemplification, ingratiation, and selfpromotion) and negative (i.e., intimidation and supplication) tactics aggregated together, and described their use in general, as opposed to the present investigation which examines each configuration individually, as well as the potential various targets of the configurations (peers, supervisors, and subordinates/support staff).

Political skill has been conceptualized as the mechanism by which individuals in organizations achieve their goal-directed behavior, which occurs through the proper execution of power and influence over others (Ferris et al., 2007). This conceptualization extends the work of Jones (1964), who argued that personal goals activate ingratiatory behavior as a function of the importance of the goal, the ability of the target to provide the goal, and the susceptibility of the target to the influence attempt. This mirrors the process of impression construction outlined by Leary and Kowalski (1990), and it has been long argued that political skill is a personal resource by which individuals properly assess and execute this process of selecting the right tactic or strategy (Ferris et al., 2007).

More specifically, politically skilled individuals are masters of extracting social cues from their environment, understanding the appropriate norms of behavior, and then selecting the 
proper interpersonal course of action (Ferris et al., 2007). Leary and Kowalski (1990) argued that impression construction is a function of how focal individuals perceive their own self-concept, the desirability of their conveyed identity image, constraints associated with the social role they are performing, and values of the target individuals. Politically skilled individuals exhibit a calm confidence and high self-efficacy (Ferris et al., 2007), and thus likely will select impression management tactics that demonstrate these positive attributes, as it is largely how they see themselves. Additionally, the selection of impression management tactics is context dependent (Bolino et al., 2015), and thus determining which identity images are desirable or undesirable due to different role constraints or target preferences requires a well-calibrated social perception. Politically skilled individuals are equipped with this resource, and thus can read social settings and strategically chose to emote the socially acceptable aspects of their identity to others.

Unlike positive impression management tactics, which are meant to generate favorable images of the focal individual and generally adhere to social norms, negative tactics (i.e., supplication and intimidation) create unfavorable impressions. Supplication is often used to provoke others to lend assistance or in order to avoid a task (Becker \& Martin, 1995), and is widely thought to be counterproductive to most performance outcomes. Although less is known about the effects of intimidation, in most organizations, it would be viewed as counternormative. Certainly in athletic or military arenas, intimidation could be viewed as a more appropriate norm of behavior (Bolino et al., 2015), but these contexts are unique departures from those of traditional organizations. Because politically skilled individuals recognize that the use of supplication and intimidation is counterproductive to goal-related activities within traditional contexts, generally, they would avoid negative tactics. Thus, we hypothesize that: 
Hypothesis 2: Political skill is associated with the selection of impression management configurations, such that those highest in political skill are most likely to select a positive impression management strategy.

Political will. Mintzberg (1983) argued that in order for individuals to survive within a political arena, they must possess both political skill and political will. Although political skill has received the most scholarly attention, these two constructs in tandem are theoretically vital to understanding which individuals are likely to select and employ particular impression management strategies. Formally defined, political will is "the motivation to engage in strategic, goal-directed behavior that advances the personal agenda and objectives of the actor that inherently involves the risk of relational or reputational capital” (Treadway, 2012, p. 533).

Recently, Kapoutsis et al. (in press) developed and empirically tested a scale for political will, which was shown to predict a host of political behaviors including ingratiation, upward appeals, and voice behavior. If skillfully implemented, political behaviors can be the means of acquiring resources that fulfill needs (Kapoutsis et al., in press). Thus, political will is rooted in self-determination theory (Ryan \& Deci, 2000), which asserts that individuals are intrinsically motivated to engage in behaviors that fulfill their needs for competence, relations, and autonomy. Exerting influence, developing liking, amassing power, building trust, and other behaviors that are motivated by political will help to meet these needs, and thus may be intrinsically motivating within the organizational context (Treadway et al., 2005).

Because impression management motivation is driven by goal relevance and the value placed on goals (Leary \& Kowalski, 1990), political will should be a primary predictor of impression management behavior. Individuals with high political will recognize and espouse the virtues of political behavior, and thus identify the need to manage impressions when achieving 
goals within the organizational context. Additionally, individuals with high political will are intrinsically, rather than extrinsically, motivated to achieve their organizational goals, and this natural drive to achieve is the highest form of motivation (Ryan \& Deci, 2000). Thus, they place a higher value on their goals, and will demonstrate behaviors to achieve their goals.

Political behaviors, such as impression management, often are discretionary influence attempts, and thus inherently involve risk of personal and reputational resources (Treadway, 2012). Thus, there are potential repercussions for exhibiting such behaviors, and this intrapsychic appraisal has the potential to deter some individuals from engaging in them. For this reason, Harris et al. (2016) argued that political will has diminishing returns, and can be detrimental if political behaviors are not used discriminately. Their proposition is consistent with the findings of Bolino and Turnley (2003), who found that aggressives (i.e., those who use impression management tactics indiscriminately at high levels) were the least desirable colleagues with whom to work. This is in stark contrast to positives, who were the most desirable colleagues with whom to work, and who we argue hold the highest level of political skill.

Political skill and political will are modestly correlated constructs (Kapoutsis et al., in press), and those with political skill and political will have both the motivation to engage in goaldirected behavior, and the discriminating sense to know how and when to select appropriate forms of influence. Because of the diminishing returns of political will (Harris et al., 2016), politically skilled positives likely recognize that there is an optimal level of impression management, and that too much will be perceived as overbearing or insincere by their targets.

Those who have high political will, but low political skill, likely do not properly identify the perils of overuse of impression management tactics. They use a high frequency of influence tactics that are not properly selected or calibrated, whereas those with low political will are likely 
to refrain from these behaviors altogether. Thus, aggressives should demonstrate the highest level of political will, and passives should exhibit the lowest level. Knowing that there is likely an optimal level of political behavior, and that politically skilled individuals are likely to appropriately diagnose this level of behavior, it stands to reason that positives will show a medium level of political will. So, we hypothesize the following:

Hypothesis 3: Political will is associated with the selection of impression management configurations, such that the aggressives will be associated with the highest level of political will, passives will be associated with the lowest level of political will, and positives will be associated with the median level of political will.

\section{Method}

\section{Plan of the Research}

This investigation is divided into three studies, which draw upon four distinct samples to evaluate our hypotheses. Hochwarter, Ferris, and Hanes (2011) have argued for the importance of multi-study and multi-sample investigations as they improve the validity and generalizability of research findings. The purpose of Study 1 is to constructively replicate the cluster solution and configurational pattern of impression management tactics found by Bolino and Turnley (2003). We extend their work by not only evaluating at the mean frequency level of the different impression management tactics, but also distinguishing at whom the target of the behavior was aimed (i.e., supervisors, subordinates, and coworkers/support staff). These variables were included for exploratory purposes to see if any patterns emerged across samples with respect to variation in tactics based on the target. Study 1 - Sample 1 draws upon a student recruited sample from a large university in the Southeastern United States in order to address Hypotheses 1a and $1 b$. 
The purpose of Study 2 is to evaluate the manner in which political skill predicts these clusters (i.e., evaluate Hypothesis 2). Study 2 - Sample 1 is the same sample used in Study 1. Study 2 - Sample 2 is comprised of participants from a large automotive organization in the Southeastern United States. Study 2 - Sample 3 draws upon human resource professionals working in Brazilian organizations, and serves to further replicate and extend our findings using subjects from an international context (i.e., addressing Hypotheses 1b and 2). Lastly, Study 3 utilizes student-recruited subjects to evaluate the role of political skill and will in predicting impression management configurations (i.e., addressing Hypothesis 3), controlling for the effects of self-monitoring and Machiavellianism, which were found to be associated with impression management configurations by Bolino and Turnley (2003).

\section{Participants and Procedures}

Study 1 and 2 (Sample 1). Consistent with other multi-sample designs (Hochwarter, 2014), students in an undergraduate management class recruited participants for Sample 1. Students were given course credit for their assistance recruiting participants who were full-time employees. A final usable sample of 168 participants was analyzed (54\% female, $M_{a g e}=39.6$ years, $M_{\text {org. tenure }}=7.6$ years). This study serves as Sample 1 for both Study 1 and Study 2 .

Study 2 (Sample 2). Paper surveys were sent via interoffice mail to 758 employees of an automotive organization in the southeastern United States. The surveys were collected from the employees by one of the authors in order to ensure confidentiality within the organization. A total of 369 employee responses were received, yielding a $48.6 \%$ response rate, and after deleting cases that did not provide information on variables used in this study, data from the final sample of 245 participants $\left(37 \%\right.$ female, $M_{a g e}=39.8$ years, $M_{\text {org } \text {. tenure }}=5$ years $)$ were used in the analysis. 
Study 2 (Sample 3). Paper surveys were provided to 457 Human Resource (HR) professionals from a wide range of organizations (e.g., public administration, education, health care, financial services, and transportation) in three Brazilian cities (Porto Alegre, São Paulo, and Brasília). The survey was designed in English, translated into faluese, and translated back into English by two independent translators. In total, completed questionnaires were received from 320 employees for a $70 \%$ response rate (52\% female, $M_{a g e}=36.8$ years, $M_{\text {org } \text {. tenure }}=9.2$ years) .

Study 3 (Sample 4). For Study 3 - Sample 4, the sample was comprised of full-time employees who were recruited by management students at a large university in the Southeastern United States, and data collection procedures were consistent with the recommendations by Wheeler, Shanine, Leon, and Whitman (2013). Participants received a link to a Qualtrics survey from the participants, and completed the survey online. Originally, 520 participants filled out surveys. After eliminating cases who failed an instructed item, as well as participants who did not respond to certain measures, the final sample analyzed in this study was comprised of 452 individuals (53\% female, $M_{a g e}=52.1$ years, $M_{\text {org } \text {. tenure }}=10.6$ years $)$.

\section{Measures}

Impression management. Impression management was measured using the scale developed by Bolino and Turnley (1999), which measures intimidation, supplication, exemplification, ingratiation, and self-promotion. Participants responded to these questions using a 5-point Likert-type scale (1 - never behave this way, 5 - often behave this way), and answered these questions in regard to their use of the tactic directed towards peers, supervisors, and subordinates / support staff. Sample items included “Act like you know less than you actually know so people will help you out," "Be intimidating with people when it will help you get your 
job done," "Compliment people so they will see you as likable," and "Talk proudly about your experience or education.”

The following alpha reliabilities for each impression management tactic were calculated using all items covering the three directions (i.e., peers, subordinates/support staff, and supervisors). All alpha reliabilities for directionally specific tactics (e.g., intimidation with peers) were above the generally accepted .70 cutoff. For Study 1 and Study 2 (which both used Sample 1), the alpha reliabilities for intimidation, supplication, exemplification, ingratiation, and selfpromotion were 89, .94, .93, .93, .95, respectively. For Study 2 - Sample 2, the alpha reliabilities for intimidation, supplication, exemplification, ingratiation, and self-promotion were .92, .94, .94, .93, and .94, respectively. For Study 2 - Sample 3, the alpha reliabilities for intimidation, supplication, exemplification, ingratiation, and self-promotion were $.89, .92, .90, .90$, and .93 , respectively. Lastly, for Study 3, the alpha reliabilities for intimidation, supplication, exemplification, ingratiation, and self-promotion were $.94, .96, .94, .94$, and .95 , respectively.

Political skill. Political skill was measured using the 18-item Political Skill Inventory (PSI) (Ferris et al., 2005). Responses were measured using a Likert-type scale (1 - strongly disagree, 7 - strongly agree). Sample items included "I am able to communicate easily and effectively with others," "I spend a lot of time and effort networking with others," and "It is important that people believe I am sincere in what I say and do.” The alpha reliabilities for this scale were .92 for Study 1 and Study 2 (both using Sample 1), .89 in Study 2 - Sample 2, .90 in Study 2 - Sample 3, and .93 in Study 3 - Sample 4. These alpha reliabilities scores are consistent with those found in prior empirical studies of political skill (e.g., Andrews, Kacmar, \& Harris, 2009; Liu et al., 2007). 
Political will. Political will was measured using the 8-item Political Will Scale (PWS) (Kapoutsis et al., in press). Participants responded to items using a 7-point Likert-type scale (1 strongly disagree, 7 - strongly agree). Sample items include "Engaging in politics is an attractive means to achieve my personal objectives," "I would engage in politics to serve the common good," and "I would use political tactics to improve my working conditions.” The alpha reliability for this scale was .91 in Study 3 - Sample 4, which is consistent with the original measure development piece (Kapoutsis et al., in press).

Control variables. Bolino and Turnley (2003) found that Machiavellianism and selfmonitoring were uniquely associated with the impression management configuration that they identified. Thus, both of these constructs are included in Study 3 - Sample 4 as control variables to assess whether or not political skill and political will provide greater predictive ability. Both measures demonstrated

Machiavellianism is the extent to which individuals hold a cynical view of society, and are morally comfortable with the manipulation of others for personal gain (Christie \& Geis, 1970). High self-monitors display chameleon like social-adaptation, and control their expressive behavior accordingly (Snyder, 1974). Specifically, Bolino and Turnley (2003) found that high self-monitors are more likely to be positives, and that high Machs are more likely to be aggressives, which is consistent with the two-component model proposed by Leary and Kowalski (1990).

However, we argue that the construct domains of political skill and political will more closely represent the two components of impression management. Political will should be a more robust predictor of impression management profiles than Machiavellianism, as individuals engage in political goal-directed behavior, not just for their own selfish motivations (Leary \& 
Kowalski, 1990), but also for the benefit of others (Kapoutsis et al., in press). Political skill and self-monitoring are related but distinct constructs, and one of the differences is that, whereas self-monitors focus on being likeable and conforming to different social norms, politically skilled individuals use their socially adaptable qualities to achieve goal-directed behavior, which is a primary antecedent of impression management selection (Leary \& Kowalski, 1990).

Machiavellianism was measured using the 20-item measure developed by Christie and Geis (1970). Participants responded to items using a 5-point Likert-type scale (1 - strongly disagree, 5 - strongly agree). Sample items include “Anyone who completely trusts anyone else is asking for trouble," “Never tell anyone the real reason you did something unless it is useful to do so," "The biggest difference between most criminals and other people is that the criminals are stupid enough to get caught.” The alpha reliability for this scale was .70.

Self-monitoring was measured using the 18-item measure developed by Gangestad and Snyder (1985). Participants responded to items using a 5-point Likert-type scale (1 - strongly disagree, 5 - strongly agree). Sample items for this measure include "I would not change my opinions (or the way I do things) in order to please someone or win their favor," "I would probably make a good actor," and "I can look anyone in the eye and tell a lie with a straight face (if for a right end).” The alpha reliability for this scale was .70.

\section{Data Analysis}

Cluster analysis was used to confirm the distinguishable profiles or configurations found by Bolino and Turnley (2003), by using 15 different directional impression management scores, five impression management tactics (i.e., supplication, intimidation, ingratiation, exemplification, and self-presentation), and three directional components of each tactic (i.e., supervisor, peers, and subordinate/support staff). Cluster analysis groups data into different 
distinct configurations through a process that maximizes within-cluster homogeneity and between-cluster heterogeneity (Hair, Black, Babin, \& Anderson, 2010). Scholars have advocated for the use of two steps in this process (Ketchen \& Shook, 1996).

First, hierarchical algorithms are the preferred method for determining the number of clusters that are present in the data (Hair et al., 2010). For Sample 1, Ward’s combination procedure was employed to determine the number of clusters present in the data based on the squared Euclidian distance. This method was selected because the cluster sizes were not expected to be radically dissimilar from each other (Ketchen \& Shook, 1996). Second, nonhierarchical methods are preferable for determining cluster membership because this technique is iterative in nature. This process allows observations to switch membership (Aldenderfer \& Blashfield, 1984; Hair Anders, Tatham, \& Black., 1992), and is able to optimize the betweengroup heterogeneity and within-group homogeneity. One drawback of this procedure is that clusters must be specified a priori (Milligan, 1980). In concert, the hierarchical procedure can assist researchers in determining the likely number of clusters present, and this solution can be utilized in the non-hierarchical, or k-means, procedure to optimally assign cases to different clusters.

In this investigation, the purpose of Study 1 is to replicate the three-cluster solution (i.e., positives, aggressives, and passives) found by Bolino and Turnley (2003), using Sample 1 data. All samples from Studies 2 and 3 seek to draw on the pattern of this three-cluster solution, and demonstrate that political skill (Study 2 - Sample 1, 2, and 3; Study 3) and political will (Study 3) combine to predict these clusters. This is accomplished through discriminant analysis, which is utilized in designs that seek to predict known categorical dependent variables (i.e., cluster membership) using a set of interrelated variables (McLachlan, 2004) (i.e., political skill and 
political will). This is achieved through the use of discriminant functions, which creates a linear combination of variables that maximize the difference between groups (Tatsuoka, 1970). In this investigation, both cluster analyses and discriminant analyses were performed using SPSS software. Statistical procedures and checks for multivariate assumptions followed the recommendations of Hair and colleagues (2010). Specifically, discriminant analysis is subject to the assumptions of independent variable normality and equality of covariance matrices, and neither were determined to be problematic in our analyses. Lastly, in order to determine whether our data were tainted by the effects of common method bias, we determined the relative magnitude of our trait and method variance (Cote \& Buckley, 1988; Podsakoff, MacKenzie, \& Podsakoff 2012). Our analyses revealed that common method bias did not appear to be problematic in our dataset analyses.

\section{Results}

\section{Study 1}

The purpose of Study 1 is to confirm the three-cluster solution found by Bolino and Turnley (2003). Hypothesis 1a seeks to assess whether three clusters is an empirically appropriate solution, and Hypothesis 1b seeks to assess whether those clusters match the form of the passives, aggressives and positives found by Bolino and Turnley (2003) There are many different ways for researchers to derive the hierarchical clusters solution, including the use of previous theory, agglomeration coefficient breaks, a priori theory, dendogram observation (Ketchen \& Shook, 1996), and the examination of statistics such as the pseudo-F statistic (Calinski \& Harabasz, 1974) that measure within-group homogeneity and between-group heterogeneity. In this study, the use of agglomeration coefficient examination breaks and the 
maximization of the pseudo- $F$ statistic were used to confirm the three-cluster solution previously theorized and empirically supported by Bolino and Turnley (2003).

Sample 1. The descriptive statistics and bivariate relationships for Sample 1 (used in Study 1 and 2) are displayed in Table 1.

Insert Table 1 about here

In order to confirm the three-cluster solution found by Bolino and Turnley (2003), the agglomeration coefficient schedule was examined for large increases in the data. A large jump in the sequential agglomeration coefficients indicates that two dissimilar clusters have been grouped together (Aldenderfer \& Blashfield, 1984). One drawback to this method is that it is a subjective assessment made by the researcher as to what constitutes a sufficient jump. This is especially problematic when there is not a clear break in the data, or when there are several large breaks in the data. This may suggest that there are no clusters within the data, or that there are multiple natural sets of clusters (Ketchen \& Shook, 1996).

The results from Sample 1 support either a three- or four-cluster solution, as a moderate break in the data occurs at four clusters, and then a more pronounced break occurs at three clusters. In order to determine which solution is most appropriate, the pseudo- $F$ statistic (Calinski \& Harabasz, 1974) was calculated and charted for 2-6 cluster solutions. This analysis confirmed that three clusters was the solution that maximized between-cluster heterogeneity and within-cluster homogeneity, as the pseudo-F statistic was optimized at this solution. The evidence provided by a priori theory (Bolino \& Turnley, 2003), the break in the agglomeration 
schedule, and the optimization of the pseudo- $F$ statistic demonstrates that three clusters is the best solution, which provides support for Hypothesis 1a.

With the three-cluster solution confirmed, the second objective was to confirm the nature of the clusters, and if they match the pattern of passives, aggressives, and positives. K-means cluster analyses were performed on Sample 1, and the resulting pattern of impression management tactic types and directions were evaluated. Figure 1 displays the results of Sample 1, and impression management tactics are grouped by type and direction, and the corresponding mean frequency levels.

As hypothesized, cluster 1 participants (i.e., aggressives) chose to use all tactics at high levels of frequency, cluster 2 participants (i.e., passives) chose to use all tactics at low levels of frequency, and cluster 3 participants (i.e., positives) chose to use negative tactics at a low level of frequency (i.e., supplication and intimidation) and positive tactics (i.e., exemplification, selfpresentation, and ingratiation) at high levels of frequency. These findings replicate the results of Bolino and Turnley (2003), which provides support for Hypothesis 1b.

Insert Figure 1 about here

\section{Study 2}

Study 1 confirmed that the cluster solution, and nature of the clusters, is consistent with passives, aggressives, and positives. The purpose of Study 2 is to predict these clusters using political skill, and thus evaluate Hypothesis 2. Sample 1 is comprised of student-recruited subjects (and is the same sample utilized in Study 1), Sample 2 draws upon subjects from workers at an automotive organization, and Sample 3 is comprised exclusively of HR employees 
from a Brazilian context. The efficacy of political skill as a predictor of cluster membership is evaluated using discriminant analysis across Study 2 - Samples 1-3. Furthermore, the results of unpaired $t$-tests and Hedges' $g$ statistic (Hedges, 1982) are provided to evaluate the statistical significance and effect size of the mean differences between clusters on political skill. The Hedges' is similar in calculation and interpretation to Cohen’s d (i.e., small - .20, medium - .50, and large - .80), but is different in the way that it accounts for differing sample sizes between groups.

Sample 1. Results from the discriminant analysis provide evidence that political skill is indeed a significant predictor of impression management strategies $(\Lambda=.84, F(2,165)=15.71, p$ $<.001$ ), and the squared canonical correlation was .16, which can be interpreted similarly to $r^{2}$ in ordinary least squares (OLS) regression. Cohen (1992) established practical guidelines for interpreting effect sizes, and suggested that small, medium, and large effect sizes for $r$ are .10, .30 , and .50 , respectively. Based on these guidelines, we can extrapolate that the corresponding $r^{2}$ values for small, medium, and large percentages of variance explained are .01, .09, and .25, respectively. This indicates that, in this sample, political skill has a moderate predictive effect in the model. The mean level of political skill for cluster 1 (i.e., aggressives, $N=26$ ) was 5.02 , for cluster 2 (i.e., passives, $N=84$ ) was 5.46, and for cluster 3 (i.e., positives, $N=58$ ) was 5.96 . Unpaired $t$-tests confirmed that all three contrasts were statistically significant (positives and aggressives $g=1.06, p<.01$; positives and passives $g=.62, p<.01$; passives and aggressives $g$ $=.55, p<.01$ ), and this set of analyses provide support for Hypothesis 2 . The summary table for the discriminant analyses for Study 2 are provided in Table 4.

Sample 2. The descriptive statistics and bivariate relationships for Study 2 - Sample 2 are displayed in Table 2. Figure 2 displays the different impression management tactics by type and 
direction, and the corresponding mean frequency levels. Similar to the results from Sample 1, cluster 1 participants (i.e., passives) chose to use all tactics at low levels of frequency, cluster 2 participants (i.e., positives) chose to use negative tactics at a low level of frequency (i.e., supplication and intimidation) and positive tactics (i.e., exemplification, self-presentation, and ingratiation) at high levels of frequency, and cluster 3 participants (i.e., aggressives) chose to use all tactics at high levels of frequency.

Insert Table 2 and Figure 2 about here

Results for the discriminant analysis provide evidence that political skill is indeed a significant predictor of impression management strategies $(\Lambda=.94, F(2,317)=11.01, p<.001)$, and the squared canonical correlation was .07, which indicates that in this sample, political skill approaches a medium level of predictive ability in the model. The mean level of political skill for cluster 1 (i.e., positives, $N=147$ ) was 5.27, for cluster 2 (i.e., aggressives, $N=62$ ) was 4.91, and for cluster 3 (i.e., passives, $N=111$ ) was 4.83 . Unpaired $t$-tests confirmed that the political skill of subjects in cluster 1 (i.e., positives) was higher than for those individuals in cluster 2 (i.e. aggressives, $g=.65, p<.01$ ) and cluster 3 (i.e., passives, $g=.62, p<.01$ ), but that there was no statistical difference between the means of political skill for the aggressives and passives ( $p=$ .56). This provides support for Hypothesis 2.

Sample 3. The descriptive statistics and bivariate relationships for Study 2 - Sample 3 are displayed in Table 3. Because the samples utilized by Bolino and Turnley (2003), as well as the other samples in this investigation, utilized data from subjects within the United States, replication with an international sample provides the opportunity to see if the patterns generalize 
to a different cultural context. Figure 3 displays the different impression management tactics by type and direction, and the corresponding mean frequency levels. In the same pattern as Samples 1 and 2, cluster 1 participants (i.e., positives) chose to use negative tactics at a low level of frequency (i.e., supplication and intimidation) and two of the positive tactics (i.e., selfpresentation, and ingratiation) at high levels of frequency. However, Sample 3 participants classified as positives indicated that they used exemplification at a rate that is more consistent with how they utilize negative tactics. Cluster 2 participants (i.e., aggressives) chose to use all tactics at high levels of frequency, whereas cluster 3 participants (i.e., passives) chose to use all tactics at low levels of frequency.

Insert Table 3 and Figure 3 about here

Results for the discriminant analysis provide evidence that political skill is indeed a significant predictor of impression management strategies $(\Lambda=.91, F(2,242)=11.34, p<.001)$, and the squared canonical correlation was .09, which indicates that in this sample, political skill demonstrates moderate predictive ability in the model.. The mean level of political skill for cluster 1 participants (i.e., passives, $N=129$ ) was 5.20, for cluster 2 participants (i.e., positives, $N=83$ ) was 5.66, and for cluster 3 participants (i.e., aggressives, $N=33$ ) was 5.24. Unpaired $t$ tests confirmed that the political skill of subjects in cluster 2 (i.e., positives) was higher than for individuals in cluster 3 (i.e. aggressives, $g=.53, p<.01$ ) and cluster 1 (i.e., passives, $g=.68, p<$ .05), but that there was no statistical difference between the means of political skill for clusters 1 and $3(p=.76)$. This provides support for Hypothesis 2 . The summary results for all discriminant analyses for Study 2 are provided in Table 4. 
Insert Table 4 about here

\section{Study 3}

The primary objective of Study 3 is to assess whether political skill and political will predict the selection of impression management strategies. The analyses performed in this study are the same as Study 2, but with political will included in the model as a predictor. Additionally, the discriminant analysis also was run with Machiavellianism and self-monitoring included as control variables because they originally were theorized to be associated with impression management configuration selection by Bolino and Turnley (2003). The descriptive statistics and bivariate relationships for Study 3 - Sample 4 are displayed in Table 5. Furthermore, the results of unpaired $t$-tests and Hedges' $g$ statistic are provided to evaluate the statistical significance and effect size of the mean differences between clusters on political skill and political will.

Insert Table 5 about here

Figure 4 displays the different impression management tactics by type and direction, and the corresponding mean frequency levels. Similar to Samples 1-3, cluster 1 participants (i.e., positives) chose to use negative tactics at a low level of frequency (i.e., supplication and intimidation) and positive tactics (i.e., exemplification, self-presentation, and ingratiation) at high levels of frequency, cluster 2 participants (i.e., passives) chose to use all tactics at low levels of frequency, and cluster 3 participants (i.e., aggressives) chose to use all tactics at high levels of frequency. 
Insert Figure 4 about here

Results from the discriminant analysis provide evidence that political will $(\Lambda=.79, F(2$, $306)=40.31, p<.001)$ and political skill $(\Lambda=.93, F(2,306)=11.44, p<.001)$ are significant predictors of impression management strategies. Function 1 accounted for $90.6 \%$ of the explained variance and had a squared canonical correlation of .22, which indicates a rather large amount of variance explained. Function 2 accounted for $9.4 \%$ of the explained variance and had a squared canonical correlation of .03 , which indicates a relatively modest amount of variance explained.

The mean level of political skill for cluster 1 participants (i.e., positives, $N=120$ ) was 5.62, for cluster 2 participants (i.e., passives, $N=132$ ) was 5.14, and for cluster 3 participants (i.e., aggressives, $N=57$ ) was 5.43. Unpaired $t$-tests confirmed that the political skill of individuals in cluster 1 (i.e., positives) was higher than for individuals in cluster 2 (i.e. passives, $g=.62, p<.01$ ) but not cluster 3 (i.e., aggressives, $g=.25, p=.12$ ), and there was a statistically significant difference between the means of political skill for clusters 2 and 3 ( $g=.55, p<.05)$. These findings provide partial support for Hypothesis 2.

The mean level of political will for cluster 1 participants (i.e., positives) was 3.83, for cluster 2 participants (i.e., passives) was 2.97, and for cluster 3 participants (i.e., aggressives) was 4.42. Unpaired $t$-tests confirmed that the political will of subjects in cluster 3 (i.e., aggressives) was higher than for individuals in cluster 1 (i.e. positives, $g=.56, p<.01$ ) and cluster 2 (i.e., passives, $g=1.25, p<.01$ ), and that cluster 1 participants had a higher level of 
political will than those in cluster $2(g=.80, p<.01)$. These findings provide support for Hypothesis 3.

The analysis also was run with Machiavellianism and self-monitoring included as covariates in order to assess the relative contribution of political skill and political will to the two personal characteristics that Bolino and Turnley (2003) used in their investigation. Due to a few excluded cases because of missing data, the cluster means for political skill and political will varied slightly from the first iteration of this analysis, but differences were very minimal and did not substantially change any of the test statistics. The summary results for the discriminant analyses for Study 3 are provided in Table 6 and Table 7.

Insert Tables 6 and 7 about here

Results from the discriminant analysis provide evidence that political will $(\Lambda=.80, F(2$, $303)=38.45, p<.001)$, political skill $(\Lambda=.93, F(2,303)=11.89, p<.001)$, Machiavellianism $(\Lambda=.79, F(2,303)=23.57, p<.001)$, and self-monitoring $(\Lambda=.79, F(2,303)=19.25, p<.001)$ all are significant predictors of impression management configuration. Function 1 accounted for $90.3 \%$ of the explained variance and had a squared canonical correlation of .30, which indicates a rather large amount of variance explained. Function 2 accounted for $9.7 \%$ of the explained variance and had a squared canonical correlation of .04, which indicates a rather modest amount of variance explained.

In order to compare the relative contribution of each variable in the analysis, potency indices were calculated for each variable (Hair et al., 2010). In descending order of contribution, the respective potency values were political will (.53), self-monitoring (.33), Machiavellianism 
(.27), and political skill (.17). Hair and colleagues (2010) suggest using caution when interpreting the results of a single discriminant analysis, as the discriminant loadings may be subject to instability.

The mean level of Machiavellianism for cluster 1 participants (i.e., positives) was 2.64, for cluster 2 participants (i.e., passives) was 2.49, and for cluster 3 participants (i.e., aggressives) was 2.84. Unpaired $t$-tests confirmed that the Machiavellianism of subjects in cluster 1 (i.e., positives) was higher than for individuals in cluster 2 (i.e. passives, $p<.01$ ) and cluster 3 (i.e., aggressives, $p<.01$ ), and there was a statistically significant difference between the means of political skill for clusters 2 and $3(p<.05)$.

The mean level of self-monitoring for cluster 1 participants (i.e., positives) was 3.07, for cluster 2 participants (i.e., passives) was 2.74, and for cluster 3 participants (i.e., aggressives) was 2.93. Unpaired $t$-tests confirmed that the self-monitoring of subjects in cluster 1 (i.e., positives) was higher than individuals in cluster 2 (i.e. passives, $p<.01$ ) but not cluster 3 (i.e., aggressives, $p=.92$ ), and there was a statistically significant difference between the means of political skill for clusters 2 and $3(p<.01)$.

\section{Discussion}

\section{Theoretical Contributions}

This multi-study investigation sought to contribute to the organizational politics literature in three ways. First, we constructively replicated the configurational impression management strategies found by Bolino and Turnley (2003), and confirmed that individuals tend to follow one of three strategies: Use of all tactics at a high level, use of all tactics at a low level, and the use positive tactics at a high level and avoid negative tactics. Second, this investigation answered the call to explore antecedents of impression management (Bolino et al., 2015) by empirically 
validating the often proposed theory (but rarely tested) that politically skilled individuals demonstrate careful selection with respect to impression management strategies. Lastly, we also demonstrated that political will is a vital component of the impression management configuration selection process, as it contributed the most to the accurate prediction of impression management configurations.

The results of hierarchical and K-means cluster analyses in four diverse samples generally supported the theory that three impression management configurations exist (i.e., positives, passives, and aggressives). The results of Study 2 - Sample 3, which was drawn from working professionals in Brazil, did not quite follow the same form as Samples 1, 2, and 4, but instead suggested that exemplification should be categorized as a negative tactic rather than a positive tactic. Although expansive investigation into cultural differences in impression management is beyond the scope of this investigation, Hofstede (1983) posited that social context creates variation in how individuals employ and perceive (Bolino et al., 2015) impression management tactics.

Individuals in cultures that emphasize harmony likely view self-focused impression management tactics differently than individuals in the U.S. (Sandal et al., 2014). Specifically, the U.S. and Brazil differ greatly on the individual-collective dimension of culture (Hofstede, 1984), and perhaps it is because of this orientation that a self-focused tactic like exemplification is culturally acceptable in an individually-focused culture like the U.S., but not in a collectivelyfocused culture like Brazil. If this is true, it is further evidence that politically skilled individuals are able to accurately evaluate and adapt to their environment, and act in ways that portray themselves in a positive light. Certainly, the field would benefit from future scholarly inquiry in this area. 
Furthermore, discriminant analysis provided empirical evidence that suggests the cluster with the highest level of political skill was the positives cluster, which suggests that politically skilled individuals consciously select tactics that will portray themselves in a positive fashion, and purposefully avoid tactics that cast themselves in a negative light. Thus, the interpersonal effectiveness process that we observe has to do, not just with the fashion in which the tactic is delivered, but in its selection, which supports theory proposed by Ferris et al. (2007). This selection process is consistent with the impression construction process proposed by Leary and Kowalski (1990). Therefore, collectively, the results of these studies suggest that political will and political skill represent two important cognitive processes that enable impression management configuration selection.

However, the findings across samples did not suggest that the difference between passives and aggressives could be consistently predicted by political skill. The results of Study 3 demonstrated that political will was the most important predictor of impression management configurations as this construct largely determines those who retract from active impression management strategies altogether, and those who indiscriminately use these strategies at high levels. This is consistent with Leary and Kowalski’s (1990) impression motivation process. Moreover, our findings support the arguments of Harris and colleagues (2016) that political will is a construct that is subject to the too-much-of-a-good-thing effect (Pierce \& Aguinis, 2013), and thus, there is an optimal level of political will that individuals can achieve.

Finally, a visual examination of the directionality of tactic use (peers, subordinates/support staff and superiors) are consistent, for the most part. That is, individuals from each of the three clusters appear to be consistent in their tactic use, regardless of the target. With that said, all clusters in one sample (Study 3 - Sample 4) appear to be utilizing 
exemplification and self-promotion at higher rates directed toward their superiors. This is logical and not unique to those high in political skill and will. Another interesting nuance may be that persons categorized in the aggressive cluster from our Brazilian sample (Study 2 - Sample 3) may be somewhat more apt to utilize intimidation directed at subordinates and less likely to utilize intimidation towards superiors. Variations in the use of intimidation may be due to the fact that Brazil is a higher power-distance culture (Hofstede, 1983), with actors accepting that power is distributed unequally. Post-hoc analysis does indicate a statistically significant difference in the use of intimidation directed towards subordinates versus superiors. However, as noted earlier, cultural differences are beyond the scope of this study, but should be investigated in future work.

\section{Strengths and Limitations}

The design of the present investigation has a few strengths that warrant mention. First, consistent with trends in research, and in order to increase validity and generalizability, the research design employed in this investigation drew upon three studies and four diverse samples to evaluate hypotheses (Hochwarter et al., 2011). Replicability is one of the most important aspects of the creation of scientific knowledge (e.g., Tsang \& Kwan, 1999), and this study constructively replicates the configurations found by Bolino and Turnley (2003), and replicates many of the present investigation's hypotheses using multiple diverse samples. Second, following methodological recommendations, survey items for some measures were separated in order to create psychological separation (Podsakoff, MacKenzie, \& Podsakoff, 2012). Third, in Study 3, we were able to control for the effects of Machiavellianism and self-monitoring, which were used as the primary predictors of impression management configurations by Bolino and Turnley (2003). The results indicate that political will is the best predictor of impression 
management configurations, above and beyond that of Machiavellianism and self-monitoring. Political skill was shown to be a significant predictor, but did not contribute to the same extent as political will, Machiavellianism, and self-monitoring.

As with all studies, the limitations of this study should be taken into consideration when assessing the results. First, the data across the studies are cross-sectional in nature, and regardless of the strength of the theoretical foundations, causality cannot be confirmed from the results. Second, another issue with cross-sectional data is that results are subject to the potential biasing effects of a common research method. In order to test for this, the Cote and Buckley (1988) method was applied, and the results revealed that the effects of trait variance were far stronger than those of method variance, which suggests that common method variance was not a problematic issue in this investigation.

\section{Future Research Directions}

It has been over three decades since Mintzberg (1983) first coined the terms political skill and political will, and with the recent development of the Political Will Scale (PWS), scholars can now empirically test the interactive and combinative effects of political will and political skill, as well as determine their antecedents. We outline an actionable agenda for future research in this area. First, the vast majority of political skill studies have explored the effects of this construct in a vacuum, and have not considered how individuals with varying levels of political skill interact with each other. Laboratory experiments, qualitative investigations, and field studies could all address the question of: What happens when individuals with varying levels of political skill and political will are engaged in a political game (e.g., a job interview, negotiation, or promotion contest)? 
Second, political skill has been conceptualized as having both inborn and malleable aspects, and can be learned through acute interaction with others (Ferris et al., 2007). Political will, which is theoretically grounded in need-based theories of motivation (Ryan \& Deci, 2000; Treadway et al., 2005), is likely to have malleable or contagious aspects. Furthermore, Kapoutsis and colleagues (in press) found evidence that political will is composed of benevolent and selfserving dimensions. This implies that people are motivated to use political behavior to achieve goals that are selfish and potentially disruptive to organizational functioning, or that have the best interests of the collective in mind. The literature on organizational politics would benefit greatly from explanations of how and under what conditions individuals develop political skill and political will (i.e., benevolent and/or self-serving motivations) over time, how dimensions of political will and political skill interact during this process, and how interpersonal mechanisms like leadership and social networks facilitate these development processes.

Lastly, evaluations of political will and political skill should be explored within different contexts at work, as the field of organizational politics determines the various ways in which these constructs impact different work outcomes. Contexts such as the employment interview and promotion processes, organizational change initiatives, formal and informal employee socialization processes, and the impact on work/family spillover have received little attention in the political skill literature. The field would benefit greatly from knowing more about the cognitive processes and behaviors that politically skilled and willed individuals experience and display in these and other contexts.

\section{Conclusion}

Over the past few decades, the scholarly advancement of political skill has provided the field of organizational politics with greater understanding of the advantages that political agents 
have as they operate within the political arena of organizations. Despite the significant progress made, important gaps still exist as we attempt to more fully understand informal political processes within the workplace. Exploring the combinative or interactional impact of political will and political skill on various organizational outcomes has great theoretical potential, and the contributions of this investigation confirm that in order to best predict the selection of impression management behaviors, one needs to account for both political skill and political will. Hopefully, this investigation will inspire future research that will expand our understanding of influence processes and organizational politics in meaningful and important ways. 
Political Skill, Political Will, Impression Management 37

\section{References}

Aldenderfer, M.S., \& Blashfield, R.K. (1984). Cluster analysis. Newbury Park, CA: Sage.

Andrews, M. C., Kacmar, K. M., \& Harris, K. J. (2009). Got political skill? The impact of justice on the importance of political skill for job performance. Journal of Applied Psychology, 94(6), 1427.

Baron, R.A., \& Markman, G.D. (2000). Beyond social capital: How social skills can enhance entrepreneurs' success. Academy of Management Executive, 14(1), 106-116.

Barsness, Z.I., Diekmann, K.A., \& Seidel, M.D.L. (2005). Motivation and opportunity: The role of remote work, demographic dissimilarity, and social network centrality in impression management. Academy of Management Journal, 48(3), 401-419.

Becker, T. E., \& Martin, S. L. (1995). Trying to look bad at work: Methods and motives for managing poor impressions in organizations. Academy of Management Journal, 38(1), 174-199.

Bing, M. N., Davison, H. K., Minor, I., Novicevic, M. M., \& Frink, D. D. (2011). The prediction of task and contextual performance by political skill: A meta-analysis and moderator test. Journal of Vocational Behavior, 79(2), 563-577.

Blickle, G., Fröhlich, J. K., Ehlert, S., Pirner, K., Dietl, E., Hanes, T. J., \& Ferris, G. R. (2011). Socioanalytic theory and work behavior: Roles of work values and political skill in job performance and promotability assessment. Journal of Vocational Behavior, 78(1), 136148.

Blickle, G., Meurs, J. A., Zettler, I., Solga, J., Noethen, D., Kramer, J., \& Ferris, G. R. (2008). Personality, political skill, and job performance. Journal of Vocational Behavior, 72(3), 377-387.

Bolino, M., Long, D., \& Turnley, W. (2015). Impression management in organizations: Critical questions, answers, and areas for future research. Annual Review of Organizational Psychology and Organizational Behavior, 3, 2.1-2.30.

Bolino, M.C., \& Turnley, W.H. (1999). Measuring impression management in organizations: A scale development based on the Jones and Pittman taxonomy. Organizational Research Methods, 2(2), 187-206.

Bolino, M.C., \& Turnley, W.H. (2003). More than one way to make an impression: Exploring profiles of impression management. Journal of Management, 29(2), 141-160.

Bourdage, J. S., Wiltshire, J., \& Lee, K. (2015). Personality and workplace impression management: Correlates and implications. Journal of Applied Psychology, 100(2), 537546. 
Brouer, R.L., Badaway, R.L., Gallagher, V.C., \& Haber, J.A. (2014). Political skill dimensionality and impression management choice and effective use. Journal of Business and Psychology, 30(2), 217-233.

Calinski, T., \& Harabasz, J. (1974). A dendrite method for cluster analysis. Communications in Statistics, 3(1), 1-27.

Christie, R., \& Geis, F. (1970). Studies in Machiavellianism. New York: Academic Press.

Cohen, J. (1992). A power primer. Psychological Bulletin, 112(1), 155-159.

Cote, J.A., \& Buckley, M.R. (1988). Measurement error and theory testing in consumer research: An illustration of the importance of construct validation. Journal of Consumer Research, 14(4), 579-582.

Diekmann, C., Blickle, G., Hafner, K., \& Peters, L. (2015). Trick or trait? The combined effects of employee impression management modesty and trait modesty on supervisor evaluations. Journal of Vocational Behavior, 89, 120-129.

Farmer, S.M., \& Maslyn, J.M. (1999). Why are styles of upward influence neglected? Making the case for a configurational approach to influences. Journal of Management, 25(5), $653-682$.

Ferris, G.R., Treadway, D.C., Perrewé, P.L., Brouer, R.L., Douglas, C., \& Lux, S. (2007). Political skill in organizations. Journal of Management, 33(3), 290-320.

Ferris, G.R., Treadway, D.C., Kolodinsky, R.W., Hochwarter, W.A., Kacmar, C.J., Douglas, C., \& Frink, D.D. (2005). Development and validation of the political skill inventory. Journal of Management, 31(1), 126-152.

Gangestad, S., \& Snyder, M. (1985). "To carve nature at its joints": On the existence of discrete classes in personality. Psychological Review, 92(3), 317-349.

Hair, J.F., Anderson, R.E., Tatham R.L, \& Black, W. C. (1992). Multivariate data analysis (3 ${ }^{\text {rd }}$ edition). New York: Macmillan.

Hair, J. F., Jr., Black, W. C., Babin, B. J., \& Anderson, R. E. (2010). Multivariate data analysis ( $7^{\text {th }}$ edition). Englewood Cliffs, NJ: Prentice Hall.

Harris, J.N., Maher, L.P., \& Ferris, G.R. (2016). The roles of political skill and political will in job performance prediction. In E. Vigoda-Gadot \& A. Drory (Eds.), Handbook of organizational politics: Looking back and to the future (Second edition, pp. 15-39). Northampton, MA: Edward Elgar Publishing, Inc. 
Hedges, L. V. (1982). Estimation of effect size from a series of independent experiments. Psychological Bulletin, 92(2), 490-499.

Hochwarter, W A. (2014). On the merits of student-recruited sampling: Opinions a decade in the making. Journal of Occupational and Organizational Psychology, 87(1), 27-33.

Hochwarter, W.A., Ferris, G.R., \& Hanes, T.J. (2011). Multi-study packages in organizational science research. In D.J. Ketchen \& D.D. Bergh (Eds.), Building methodological bridges: Research methodology in strategy and management (Vol. 6, pp. 163-199). Bingley, UK: Emerald Group.

Hofstede, G. (1983). The cultural relativity of organizational practices and theories. Journal of International Business Studies, 14(2), 75-90.

Hofstede, G. (1984). Cultural dimensions in management and planning. Asia Pacific Journal of Management, 1(2), 81-99.

Jones, E.E. (1964). Ingratiation. New York: Meredith.

Jones, E.E., \& Pittman, T.S. (1982). Toward a general theory of strategic self-presentation. In J. Suls (Ed.), Psychological perspectives on the self (pp. 231-262). Hillsdale, NJ: Erlbaum.

Kapoutsis, I., Papalexandris, A., Treadway, D.C., \& Bentley, J. (in press). Measuring political will in organizations theoretical construct development and empirical validation. Journal of Management. doi: 0149206314566460.

Ketchen, D.J., \& Shook, C.L. (1996). The application of cluster analysis in strategic management research: an analysis and critique. Strategic Management Journal, 17, 441-458.

Kipnis, D., Schmidt, S.M., Swaffin-Smith, C., \& Wilkinson, I. (1984). Patterns of managerial influence: Shotgun managers, tacticians, and bystanders. Organizational Dynamics, 12(3), 58-67.

Law, K.S., Wong, C., \& Mobley, W.H. (1998). Toward a taxonomy of multidimensional constructs. Academy of Management Review, 23(4), 741-755.

Leary, M.R., \& Kowalski, R.M. (1990). Impression management: A literature review and twocomponent model. Psychological Bulletin, 107(1), 34-47.

Liden, R.C., \& Mitchell, T.R. (1988). Ingratiatory behaviors in organizational settings. Academy of Management Review, 13(4), 572-587.

Liu, Y., Ferris, G. R., Zinko, R., Perrewé, P. L., Weitz, B., \& Xu, J. (2007). Dispositional antecedents and outcomes of political skill in organizations: A four-study investigation with convergence. Journal of Vocational Behavior, 71(1), 146-165. 
McLachlan, G. (1992). Discriminant analysis and statistical pattern recognition. New York: Wiley.

Mintzberg, H. (1983). Power in and around organizations. Englewood Cliffs, NJ: Prentice-Hall.

Milligan, G.W. (1980). An examination of the effect of six types of error perturbation on fifteen clustering algorithms. Psychometrika, 45(3), 325-342.

Munyon, T.P., Summers, J.K., Thompson, K.M., \& Ferris, G.R. (2015). Political skill and work outcomes: A theoretical extension, meta-analytic investigation, and agenda for the future. Personnel Psychology, 68(1), 143-184.

Pierce, J.R., \& Aguinis, H. (2013). The too-much-of-a-good-thing effect in management. Journal of Management, 39(2), 313-338.

Pfeffer, J. (1981). Power in organizations. Boston: Pitman.

Podsakoff, P.M., MacKenzie, S.B., \& Podsakoff, N.P. (2012). Sources of method bias in social science research and recommendations on how to control it. Annual Review of Psychology, 63, 539-569.

Rosenfeld, P. (1997). Impression management, fairness, and the employment interview. Journal of Business Ethics, 16(8), 801-808.

Ryan, R., \& Deci, E. (2000). Self-determination theory and the theory of intrinsic motivation, social development, and well-being. American Psychologist, 55(1), 68-78.

Sandal, G.M., van de Vijver, F., Bye, H.H., Sam, D.L., Amponsah, B., Cakar, N., Franke, G.H., Ismail, R., Kjellsen, K., Kosic, A., Leontieva, A., Mortazavi, S., \& Sun, C.T.-L. (2014). Intended self-presentation tactics in job interviews: A 10-country study. Journal of Cross-Cultural Psychology, 45, 939-958.

Short, J.C., Payne, G.T., \& Ketchen, D.J. (2008). Research on organizational configurations: Past accomplishments and future challenges. Journal of Management, 34(6), 1053-1079.

Snyder, M. (1974). Self-monitoring of expressive behavior. Journal of Personality and Social Psychology, 30, 526-537.

Tatsuoka, M.M. (1970). Discriminant analysis: The study of group differences. Champaign, IL: Institute for Personality and Ability Testing.

Tedeschi, J.T. (Ed.) (2013). Impression management theory and social psychological research. Cambridge, MA: Academic Press. 
Tedeschi, J.T., \& Melburg, V. (1984). Impression management and influence in the organization. In S. B. Bacharach \& E. J. Lawler (Eds.), Research in the sociology of organizations (pp. 31-58). Greenwich, CT: JAI Press.

Treadway, D.C. (2012). Political will in organizations. In G.R. Ferris \& D.C. Treadway (Eds.), Politics in organizations: Theory and research considerations (pp. 531-566). New York: Routledge, Taylor \& Francis Group.

Treadway, D.C., Hochwarter, W.A., Kacmar, C.J., \& Ferris, G.R. (2005). Political will, political skill, and political behavior. Journal of Organizational Behavior, 26(3), 229-245.

Treadway, D.C., Ferris, G.R., Duke, A.B., Adams, G.L., \& Thatcher, J.B. (2007). The moderating role of subordinate political skill on supervisors' impressions of subordinate ingratiation and ratings of subordinate interpersonal facilitation. Journal of Applied Psychology, 92(3), 848-855.

Tsang, E.W.K, \& Kwan, K. (1999) Replication and theory development in organization science: A critical realist perspective. Academy of Management Review, 24(4), 759-780.

Wayne, S.J., \& Liden, R.C. (1995). Effects of impression management on performance ratings: A longitudinal study. Academy of Management Journal, 38(1), 232-260.

Wheeler, A.R., Shanine, K.K., Leon, M.R., \& Whitman, M.V. (2014). Student-recruited samples in organizational research: A review, analysis, and guidelines for future research. Journal of Occupational and Organizational Psychology, 87(1), 1-26. 
Table 1

\begin{tabular}{|c|c|c|c|c|c|c|c|c|c|c|c|c|c|c|c|c|c|c|c|c|c|}
\hline Variable & $M$ & $S D$ & 1 & 2 & 3 & 4 & 5 & 6 & 7 & 8 & 9 & 10 & 11 & 12 & 13 & 14 & 15 & 16 & 17 & 18 & 19 \\
\hline 1 Political Skill & 5.54 & 0.81 & - & & & & & & & & & & & & & & & & & & \\
\hline 2 Supplication - Supervisor & 1.41 & 0.69 & $-.19 * *$ & - & & & & & & & & & & & & & & & & & \\
\hline 3 Supplication - Peers & 1.47 & 0.76 & $-.23^{* *}$ & $.85^{* *}$ & - & & & & & & & & & & & & & & & & \\
\hline 4 Supplication - Subordinates & 1.47 & 0.77 & $-.17 *$ & $.82 * *$ & $.87^{* *}$ & - & & & & & & & & & & & & & & & \\
\hline 5 Intimidation - Supervisor & 1.46 & 0.65 & $-.16^{*}$ & $.45^{* *}$ & $.45^{* *}$ & $.47 * *$ & - & & & & & & & & & & & & & & \\
\hline 6 Intimidation - Peers & 1.61 & 0.69 & -.12 & $.47 * *$ & $.49 * *$ & $.44^{* *}$ & $.77 * *$ & - & & & & & & & & & & & & & \\
\hline 7 Intimidation - Subordinates & 1.69 & 0.77 & $-.15^{*}$ & $.46^{* *}$ & $.46^{* *}$ & $.45^{* *}$ & $.71^{* *}$ & $.86^{* *}$ & - & & & & & & & & & & & & \\
\hline 8 Exemplification - Supervisor & 2.11 & 1.08 & .04 & $.41^{* *}$ & $.38^{* *}$ & $.34 * *$ & .13 & $.22 * *$ & $.23 * *$ & - & & & & & & & & & & & \\
\hline 9 Exemplification - Peers & 1.94 & 0.95 & .03 & $.40^{* *}$ & $.44^{* *}$ & $.38 * *$ & $.16^{*}$ & $.27^{* *}$ & $.25^{* *}$ & $.91^{* *}$ & - & & & & & & & & & & \\
\hline 10 Exemplification - Subordinates & 1.87 & 0.96 & .04 & $.38^{* *}$ & $.38 * *$ & $.41^{* *}$ & $.26 * *$ & $28 * *$ & $.32 * *$ & $.87 * *$ & $.90 * *$ & - & & & & & & & & & \\
\hline 11 Self-Promotion - Supervisor & 2.77 & 1.18 & $.30 * *$ & $.22 * *$ & $.20 * *$ & $.16^{*}$ & .13 & $.16^{*}$ & $.15^{*}$ & $.54^{* *}$ & $.51^{* *}$ & $.51^{* *}$ & - & & & & & & & & \\
\hline 12 Self-Promotion - Peers & 2.59 & 1.12 & $.26 * *$ & $.25^{* *}$ & $.29 * *$ & $.26^{* *}$ & $.15^{*}$ & $.20 * *$ & $.18^{*}$ & $.51^{* *}$ & $.55^{* *}$ & $.56^{* *}$ & $.86 * *$ & - & & & & & & & \\
\hline 13 Self-Promotion - Subordinates & 2.45 & 1.14 & $.21^{* *}$ & $.26^{* *}$ & $.26^{* *}$ & $.28^{* *}$ & $.17 *$ & $.22 * *$ & $.23^{* *}$ & $.53^{* *}$ & $.56 * *$ & $.61^{* *}$ & $.79 * *$ & $.90 * *$ & - & & & & & & \\
\hline 14 Ingratiation - Supervisor & 2.44 & 1.03 & $.27^{* *}$ & $.37^{* *}$ & $.35^{* *}$ & $.27^{* *}$ & .10 & $.19 *$ & $.18^{*}$ & $.59 * *$ & $.57 * *$ & $.52 * *$ & $.55^{* *}$ & $.58 * *$ & $.55^{* *}$ & - & & & & & \\
\hline 15 Ingratiation - Peers & 2.68 & 1.03 & $.17^{*}$ & $.35^{* *}$ & $.36^{* *}$ & $.30^{* *}$ & .11 & $.19^{* *}$ & $.17 *$ & $.62^{* *}$ & $.61^{* *}$ & $.59 * *$ & $.59 * *$ & $.58 * *$ & $.55^{* *}$ & $.85^{* *}$ & - & & & & \\
\hline 16 Ingratiation - Subordinates & 2.63 & 1.07 & $.23 * *$ & $.31^{* *}$ & $.34^{* *}$ & $.33^{* *}$ & .13 & $.18^{*}$ & $.25^{* *}$ & $.57^{* *}$ & $.57 * *$ & $.60 * *$ & $.56^{* *}$ & $.56^{* *}$ & $.54^{* *}$ & $.83^{* *}$ & $.89 * *$ & - & & & \\
\hline 17 Cluster 1 (Aggressives) & 0.15 & 0.36 & $-.24 * *$ & $.65^{* *}$ & $.67^{* *}$ & $.69^{* *}$ & $.52 * *$ & $.50 * *$ & $.48 * *$ & $.36^{* *}$ & $.35^{* *}$ & $.38^{* *}$ & $.15^{*}$ & $.22 * *$ & $.23^{* *}$ & $.18^{*}$ & $.31^{* *}$ & $.29^{* *}$ & - & & \\
\hline 18 Cluster 2 (Passives) & 0.50 & 0.50 & -.14 & $-.34 * *$ & $-.36 * *$ & $-.36 * *$ & -.15 & $-.20 *$ & $-.22 * *$ & $-.68^{* *}$ & $-.68^{* *}$ & $-.70 * *$ & $-.71^{* *}$ & $-.74^{* *}$ & $-.72^{* *}$ & $-.64^{* *}$ & $-.71^{* *}$ & $-.70^{* *}$ & $-.43 * *$ & - & \\
\hline 19 Cluster 3 (Positives) & 0.35 & 0.48 & $.34 * *$ & -.12 & -.12 & -.14 & $-.24 * *$ & $-.17 *$ & -.13 & $.45^{* *}$ & $.45^{* *}$ & $.44^{* *}$ & $.63^{* *}$ & $.61^{* *}$ & $.59 * *$ & $.54 * *$ & $.51^{* *}$ & $.51^{* *}$ & $-.31 * *$ & $-.73 * *$ & - \\
\hline
\end{tabular}


Table 2

\begin{tabular}{|c|c|c|c|c|c|c|c|c|c|c|c|c|c|c|c|c|c|c|c|c|c|}
\hline Variables & $M$ & $S D$ & 1 & 2 & 3 & 4 & 5 & 6 & 7 & 8 & 9 & 10 & 11 & 12 & 13 & 14 & 15 & 16 & 17 & 18 & 19 \\
\hline 1 Political Skill & 5.36 & 0.75 & - & & & & & & & & & & & & & & & & & & \\
\hline 2 Supplication - Supervisor & 1.35 & 0.62 & -.02 & - & & & & & & & & & & & & & & & & & \\
\hline 3 Supplication - Peers & 1.41 & 0.69 & -.07 & $.83 * *$ & - & & & & & & & & & & & & & & & & \\
\hline 4 Supplication - Subordinates & 1.42 & 0.67 & -.05 & $.78^{* *}$ & $.91^{* *}$ & - & & & & & & & & & & & & & & & \\
\hline 5 Intimidation - Supervisor & 1.42 & 0.67 & $.13^{*}$ & $.51 * *$ & $.53 * *$ & $.47 * *$ & - & & & & & & & & & & & & & & \\
\hline 6 Intimidation - Peers & 1.51 & 0.71 & .04 & $.49 * *$ & $.54 * *$ & $.48^{* *}$ & $.81^{* *}$ & - & & & & & & & & & & & & & \\
\hline 7 Intimidation - Subordinates & 1.48 & 0.66 & .06 & $.44^{* *}$ & $.50 * *$ & $.48 * *$ & $.79 * *$ & $.85^{* *}$ & - & & & & & & & & & & & & \\
\hline 8 Exemplification - Supervisor & 2.19 & 1.12 & $.29 * *$ & $.42 * *$ & $.33^{* *}$ & $.30 * *$ & $.36 * *$ & $.38 * *$ & $.33 * *$ & - & & & & & & & & & & & \\
\hline 9 Exemplification - Peers & 2.07 & 1.06 & $.29 * *$ & $.43^{* *}$ & $.38 * *$ & $.35 * *$ & $.42 * *$ & $.39 * *$ & $.38 * *$ & $.91^{* *}$ & - & & & & & & & & & & \\
\hline 10 Exemplification - Subordinates & 2.10 & 1.11 & $.28^{* *}$ & $.41^{* *}$ & $.35^{* *}$ & $.34 * *$ & $.39 * *$ & $.36^{* *}$ & $.38 * *$ & $.88^{* *}$ & $.93^{* *}$ & - & & & & & & & & & \\
\hline 11 Self-Promotion - Supervisor & 2.58 & 1.06 & $.27^{* *}$ & $.29 * *$ & $.20^{* *}$ & $.20 * *$ & $.25^{* *}$ & $.22 * *$ & $.21 * *$ & $.58^{* *}$ & $.57^{* *}$ & $.55^{* *}$ & - & & & & & & & & \\
\hline 12 Self-Promotion - Peers & 2.46 & 1.04 & $.24^{* *}$ & $.36 * *$ & $.27^{* *}$ & $.24 * *$ & $.33^{* *}$ & $.30 * *$ & $.29 * *$ & $.59 * *$ & $.65^{* *}$ & $.60 * *$ & $.88^{* *}$ & - & & & & & & & \\
\hline 13 Self-Promotion - Subordinates & 2.39 & 1.05 & $.26^{* *}$ & $.31^{* *}$ & $.21^{* *}$ & $.20 * *$ & $.26^{* *}$ & $.23 * *$ & $.27 * *$ & $.53^{* *}$ & $.60^{* *}$ & $.62 * *$ & $.81^{* *}$ & $.90 * *$ & - & & & & & & \\
\hline 14 Ingratiation - Supervisor & 2.45 & 0.98 & $.30 * *$ & $.36 * *$ & $.27^{* *}$ & $.30 * *$ & $.33^{* *}$ & $.31 * *$ & $.32 * *$ & $.65^{* *}$ & $.61^{* *}$ & $.60^{* *}$ & $.60^{* *}$ & $.58 * *$ & $.54 * *$ & - & & & & & \\
\hline 15 Ingratiation - Peers & 2.62 & 0.98 & $.31^{* *}$ & $.32 * *$ & $.24 * *$ & $.26 * *$ & $.30 * *$ & $.26^{* *}$ & $.29 * *$ & $.56 * *$ & $.56^{* *}$ & $.55^{* *}$ & $.56^{* *}$ & $.55^{* *}$ & $.48^{* *}$ & $.87^{* *}$ & - & & & & \\
\hline 16 Ingratiation - Subordinates & 2.62 & 0.99 & $.30 * *$ & $.31 * *$ & $.27 * *$ & $.30 * *$ & $.30 * *$ & $.29 * *$ & $.32 * *$ & $.56 * *$ & $.55^{* *}$ & $.59 * *$ & $.54 * *$ & $.52 * *$ & $.51 * *$ & $.86^{* *}$ & $.93^{* *}$ & - & & & \\
\hline 17 Cluster 1 (Passives) & 0.53 & 0.50 & $-.26 * *$ & $-.45 * *$ & $-.36 * *$ & $-.34 * *$ & $-.36 * *$ & $-.34 * *$ & $-.34 * *$ & $-.77 * *$ & $-.78^{* *}$ & $-.77 * *$ & $-.68 * *$ & $-.72 * *$ & $-.67 * *$ & $-.70 * *$ & $-.63 * *$ & $-.64 * *$ & - & & \\
\hline 18 Cluster 2 (Positives) & 0.34 & 0.47 & $.30 * *$ & .04 & -.05 & -.06 & -.05 & -.06 & -.05 & $.56 * *$ & $.54 * *$ & $.55^{* *}$ & $.58^{* *}$ & $.59 * *$ & $.55^{* *}$ & $.58 * *$ & $.54^{* *}$ & $.53^{* *}$ & $-.76^{* *}$ & - & \\
\hline 19 Cluster 3 (Aggressives) & 0.13 & 0.34 & -.03 & $.62 * *$ & $.62 * *$ & $.58^{* *}$ & $.61 * *$ & $.59 * *$ & $.57 * *$ & $.35^{* *}$ & $.39 * *$ & $.36 * *$ & $.19 * *$ & $.24 * *$ & $.22 * *$ & $.22 * *$ & $.17^{* *}$ & $.19 * *$ & $-.42 * *$ & $-.28^{* *}$ & - \\
\hline
\end{tabular}

19 Cluster 3 (Aggressives)

$$
\begin{aligned}
& * p<.05 \\
& * * p<.01
\end{aligned}
$$




\section{Table 3}

Means, Standard Deviations and Correlations for Study 2 - Sample 3

\begin{tabular}{|c|c|c|c|c|c|c|c|c|c|c|c|c|c|c|c|c|c|c|c|c|c|}
\hline Variables & $M$ & $S D$ & 1 & 2 & 3 & 4 & 5 & 6 & 7 & 8 & 9 & 10 & 11 & 12 & 13 & 14 & 15 & 16 & 17 & 18 & 19 \\
\hline 1 Political Skill & 5.05 & 0.81 & - & & & & & & & & & & & & & & & & & & \\
\hline 2 Supplication - Supervisor & 1.68 & 0.72 & -.05 & - & & & & & & & & & & & & & & & & & \\
\hline 3 Supplication - Peers & 1.77 & 0.78 & -.03 & $.85^{* *}$ & - & & & & & & & & & & & & & & & & \\
\hline 4 Supplication - Subordinates & 1.77 & 0.79 & .00 & $.82 * *$ & $.90 * *$ & - & & & & & & & & & & & & & & & \\
\hline 5 Intimidation - Supervisor & 1.64 & 0.65 & .01 & $.56^{* *}$ & $.50 * *$ & $.48^{* *}$ & - & & & & & & & & & & & & & & \\
\hline 6 Intimidation - Peers & 1.86 & 0.71 & .02 & $.61^{* *}$ & $.62 * *$ & $.61^{* *}$ & $.77^{* *}$ & - & & & & & & & & & & & & & \\
\hline 7 Intimidation - Subordinates & 2.05 & 0.83 & .00 & $.56^{* *}$ & $.56 * *$ & $.62 * *$ & $.62^{* *}$ & $.85^{* *}$ & - & & & & & & & & & & & & \\
\hline 8 Exemplification - Supervisor & 1.79 & 0.75 & $-.13^{*}$ & $.59 * *$ & $.61^{* *}$ & $.60 * *$ & $.37 * *$ & $.53 * *$ & $.48^{* *}$ & - & & & & & & & & & & & \\
\hline 9 Exemplification - Peers & 1.74 & 0.77 & -.09 & $.59 * *$ & $.65^{* *}$ & $.64^{* *}$ & $.42^{* *}$ & $.55^{* *}$ & $.50 * *$ & $.89^{* *}$ & - & & & & & & & & & & \\
\hline 10 Exemplification - Subordinates & 1.73 & 0.74 & -.08 & $.57^{* *}$ & $.63^{* *}$ & $.65^{* *}$ & $.37 * *$ & $.53 * *$ & $.55^{* *}$ & $.84^{* *}$ & $.89 * *$ & - & & & & & & & & & \\
\hline 11 Self-Promotion - Supervisor & 2.94 & 0.98 & $.26^{* *}$ & $.42^{* *}$ & $.39 * *$ & $.36^{* *}$ & $.40^{* *}$ & $.43^{* *}$ & $.38 * *$ & $.41^{* *}$ & $.31^{* *}$ & $.29 * *$ & - & & & & & & & & \\
\hline 12 Self-Promotion - Peers & 2.83 & 0.97 & $.27 * *$ & $.44^{* *}$ & $.45^{* *}$ & $.41^{* *}$ & $.36^{* *}$ & $.42 * *$ & $.35^{* *}$ & $.39 * *$ & $.37^{* *}$ & $.33^{* *}$ & $.85^{* *}$ & - & & & & & & & \\
\hline 13 Self-Promotion - Subordinates & 2.79 & 0.98 & $.26^{* *}$ & $.47^{* *}$ & $.46^{* *}$ & $.47^{* *}$ & $.38^{* *}$ & $.44^{* *}$ & $.44^{* *}$ & $.40^{* *}$ & $.36^{* *}$ & $.40 * *$ & $.81^{* *}$ & $.86^{* *}$ & - & & & & & & \\
\hline 14 Ingratiation - Supervisor & 2.23 & 0.87 & .08 & $.52 * *$ & $.47 * *$ & $.47 * *$ & $.28^{* *}$ & $.43^{* *}$ & $.39 * *$ & $.57 * *$ & $.49 * *$ & $.48^{* *}$ & $.56^{* *}$ & $.53 * *$ & $.53^{* *}$ & - & & & & & \\
\hline 15 Ingratiation - Peers & 2.41 & 0.89 & .07 & $.54 * *$ & $.56 * *$ & $.52 * *$ & $.27^{* *}$ & $.39 * *$ & $.36^{* *}$ & $.52^{* *}$ & $.50 * *$ & $.48^{* *}$ & $.51^{* *}$ & $.57 * *$ & $.51^{* *}$ & $.84^{* *}$ & - & & & & \\
\hline 16 Ingratiation - Subordinates & 2.43 & 0.90 & $.12 *$ & $.50 * *$ & $.51 * *$ & $.51 * *$ & $.25^{* *}$ & $.38 * *$ & $.38 * *$ & $.48^{* *}$ & $.42 * *$ & $.46^{* *}$ & $.50 * *$ & $.53 * *$ & $.55^{* *}$ & $.79 * *$ & $.90^{* *}$ & - & & & \\
\hline 17 Cluster 1 (Positives) & 0.46 & 0.50 & $.25^{* *}$ & $-.12 *$ & -.06 & -.07 & -.03 & -.06 & -.05 & -.06 & -.07 & -.09 & $.35^{* *}$ & $.32 * *$ & $.31^{* *}$ & $.15^{* *}$ & $.22 * *$ & $.25^{* *}$ & - & & \\
\hline 18 Cluster 2 (Passives) & 0.19 & 0.40 & -.08 & $.72 * *$ & $.67 * *$ & $.67 * *$ & $.49 * *$ & $.60^{* *}$ & $.59 * *$ & $.66^{* *}$ & $.67 * *$ & $.67 * *$ & $.39 * *$ & $.42 * *$ & $.45^{* *}$ & $.55^{* *}$ & $.50 * *$ & $.45^{* *}$ & $-.45^{* *}$ & - & \\
\hline 19 Cluster 3 (Aggressives) & 0.35 & 0.48 & $-.20 * *$ & $-.47 * *$ & $-.49 * *$ & $-.49 * *$ & $-.37 * *$ & $-.44 * *$ & $-.43^{* *}$ & $-.49 * *$ & $-.48 * *$ & $-.45^{* *}$ & $-.69 * *$ & $-.69 * *$ & $-.69 * *$ & $-.61^{* *}$ & $-.64 * *$ & $-.64 * *$ & $-.67 * *$ & $-.36 * *$ & - \\
\hline
\end{tabular}

19 Cluster 3 (Aggressives)

$$
\begin{aligned}
& { }^{*} p<.05 \\
& { }^{* *} p<.01
\end{aligned}
$$




\section{Table 4}

\begin{tabular}{|c|c|c|c|}
\hline \multicolumn{4}{|c|}{ Summary of Discriminant Analysis for Study 2} \\
\hline Variables and Parameters & Sample 1 & Sample 2 & Sample 3 \\
\hline $\bar{N}$ & 168 & 245 & 320 \\
\hline \multicolumn{4}{|l|}{ Passives } \\
\hline Number of Cases & 84 & 129 & 111 \\
\hline Political Skill $M$ & 5.46 & 5.2 & 4.83 \\
\hline Political Skill SD & 0.75 & 0.63 & 0.77 \\
\hline \multicolumn{4}{|l|}{ Aggressives } \\
\hline Number of Cases & 26 & 33 & 62 \\
\hline Political Skill $M$ & 5.02 & 5.24 & 4.91 \\
\hline Political Skill SD & 0.91 & 0.94 & 1.07 \\
\hline \multicolumn{4}{|l|}{ Positives } \\
\hline Number of Cases & 58 & 83 & 147 \\
\hline Political Skill $M$ & 5.96 & 5.66 & 5.27 \\
\hline Political Skill SD & 0.65 & 0.73 & 0.65 \\
\hline Wilks Lambda & 0.84 & 0.91 & 0.91 \\
\hline$p$-value & $<.001$ & $<.001$ & $<.001$ \\
\hline Squared Canonical Correlation & 0.16 & 0.06 & 0.09 \\
\hline
\end{tabular}


Table 5

\begin{tabular}{|c|c|c|c|c|c|c|c|c|c|c|c|c|c|c|c|c|c|c|c|c|c|c|c|c|}
\hline Variables & $M$ & $S D$ & 1 & 2 & 3 & 4 & 5 & 6 & 7 & 8 & 9 & 10 & 11 & 12 & 13 & 14 & 15 & 16 & 17 & 18 & 19 & 20 & 21 & 22 \\
\hline 1 Political Skill & 5.38 & 0.78 & - & & & & & & & & & & & & & & & & & & & & & \\
\hline 2 Political Will & 3.51 & 1.27 & $.21^{* *}$ & - & & & & & & & & & & & & & & & & & & & & \\
\hline 3 Self-Monitoring & 2.93 & 0.46 & $.32 * *$ & $.30 * *$ & - & & & & & & & & & & & & & & & & & & & \\
\hline 4 Machiavellianism & 2.60 & 0.37 & $-.21^{* *}$ & $.31 * *$ & $.24^{* *}$ & - & & & & & & & & & & & & & & & & & & \\
\hline 5 Suplication - Supervisor & 1.76 & 0.96 & .04 & $.42 * *$ & $.20^{* *}$ & $.39 * *$ & - & & & & & & & & & & & & & & & & & \\
\hline 6 Suplication - Peers & 1.77 & 0.90 & .02 & $.41^{* *}$ & $.21^{* *}$ & $.41 * *$ & $.90 * *$ & - & & & & & & & & & & & & & & & & \\
\hline 7 Suplication - Subordinates & 1.72 & 0.88 & .02 & $.37 * *$ & $.20^{* *}$ & $.36 * *$ & $.85^{* *}$ & $.90 * *$ & - & & & & & & & & & & & & & & & \\
\hline 8 Intimidation - Supervisor & 1.73 & 0.92 & .00 & $.33^{* *}$ & $.16^{* *}$ & $.32 * *$ & $.63^{* *}$ & $.60^{* *}$ & $.60 * *$ & - & & & & & & & & & & & & & & \\
\hline 9 Intimidation - Peers & 1.87 & 0.91 & .08 & $.39 * *$ & $.20^{* *}$ & $.38^{* *}$ & $.60^{* *}$ & $.65^{* *}$ & $.62 * *$ & $.82^{* *}$ & - & & & & & & & & & & & & & \\
\hline 10 Intimidation - Subordinates & 1.77 & 0.87 & .07 & $.36 * *$ & $.24 * *$ & $.32 * *$ & $.60^{* *}$ & $.62^{* *}$ & $.66 * *$ & $.78^{* *}$ & $.86^{* *}$ & - & & & & & & & & & & & & \\
\hline 11 Exemplification - Supervisor & 2.69 & 1.12 & $.28 * *$ & $.40 * *$ & $.31^{* *}$ & $.26^{* *}$ & $.52^{* *}$ & $.51^{* *}$ & $.49 * *$ & $.33^{* *}$ & $.43^{* *}$ & $.45^{* *}$ & - & & & & & & & & & & & \\
\hline 12 Exemplification - Peers & 2.41 & 1.02 & $.27^{* *}$ & $.34 * *$ & $.25 * *$ & $.22 * *$ & $.48^{* *}$ & $.52^{* *}$ & $.48 * *$ & $.36 * *$ & $.43^{* *}$ & $.46^{* *}$ & $.85^{* *}$ & - & & & & & & & & & & \\
\hline 13 Exemplification - Subordinates & 2.26 & 1.04 & $.26 * *$ & $.35 * *$ & $.28 * *$ & $.20 * *$ & $.50^{* *}$ & $.53^{* *}$ & $.57 * *$ & $.38 * *$ & $.45^{* *}$ & $.54^{* *}$ & $.77 * *$ & $.84 * *$ & - & & & & & & & & & \\
\hline 14 Self-Promotion - Supervisor & 3.06 & 1.05 & $.27 * *$ & $.35 * *$ & $.30 * *$ & $.24 * *$ & $.43 * *$ & $.44 * *$ & $.43 * *$ & $.36 * *$ & $.45 * *$ & $.45^{* *}$ & $.62 * *$ & $.58 * *$ & $.59 * *$ & - & & & & & & & & \\
\hline 15 Self-Promotion - Peers & 2.84 & 1.01 & $.28 * *$ & $.36 * *$ & $.30 * *$ & $.21 * *$ & $.40^{* *}$ & $.47 * *$ & $.43^{* *}$ & $.36 * *$ & $.46^{* *}$ & $.45^{* *}$ & $.57 * *$ & $.59 * *$ & $.59 * *$ & $.87 * *$ & - & & & & & & & \\
\hline 16 Self-Promotion - Subordinates & 2.58 & 1.11 & $.29 * *$ & $.34 * *$ & $.32 * *$ & $.15^{* *}$ & $.39 * *$ & $.41^{* *}$ & $.47 * *$ & $.35 * *$ & $.41^{* *}$ & $.51^{* *}$ & $.53^{* *}$ & $.56^{* *}$ & $.70^{* *}$ & $.79 * *$ & $.83^{* *}$ & - & & & & & & \\
\hline 17 Ingtatiation - Supervisor & 2.95 & 1.05 & $.39 * *$ & $.35 * *$ & $.28^{* *}$ & $.20^{* *}$ & $.48^{* *}$ & $.48^{* *}$ & $.44 * *$ & $.30 * *$ & $.36 * *$ & $.34^{* *}$ & $.71^{* *}$ & $.64 * *$ & $.61^{* *}$ & $.64^{* *}$ & $.60^{* *}$ & $.55^{* *}$ & - & & & & & \\
\hline 18 Ingratiation - Peers & 3.04 & 1.01 & $.39 * *$ & $.30 * *$ & $.28 * *$ & .09 & $.40^{* *}$ & $.39 * *$ & $.37 * *$ & $.23 * *$ & $.28 * *$ & $.30^{* *}$ & $.63^{* *}$ & $.60^{* *}$ & $.57 * *$ & $.58 * *$ & $.58 * *$ & $.55^{* *}$ & $.84 * *$ & - & & & & \\
\hline 19 Ingratiation - Subordinates & 2.82 & 1.08 & $.39 * *$ & $.33 * *$ & $.28^{* *}$ & .07 & $.36^{* *}$ & $.37 * *$ & $.44 * *$ & $.22 * *$ & $.29 * *$ & $.40^{* *}$ & $.57 * *$ & $.57 * *$ & $.67 * *$ & $.56^{* *}$ & $.57^{* *}$ & $.68^{* *}$ & $.74 * *$ & $.81^{* *}$ & - & & & \\
\hline 20 Cluster 1 (Passives) & 0.39 & 0.49 & $.24 * *$ & $.16^{* *}$ & $.23 * *$ & .04 & .07 & .11 & $.14 *$ & -.03 & .04 & .09 & $.38 * *$ & $.35 * *$ & $.38^{* *}$ & $.43 * *$ & $.47^{* *}$ & $.44^{* *}$ & $.46^{* *}$ & $.53^{* *}$ & $.49 * *$ & - & & \\
\hline 21 Cluster 2 (Positives) & 0.43 & 0.50 & $-.26 * *$ & $-.41^{* *}$ & $-.36 * *$ & $-.28 * *$ & $-.58 * *$ & $-.61^{* *}$ & $-.61^{* *}$ & $-.46 * *$ & $-.53 * *$ & $-.55^{* *}$ & $-.73^{* *}$ & $-.72 * *$ & $-.75^{* *}$ & $-.73^{* *}$ & $-.72^{* *}$ & $-.68^{* *}$ & $-.75 * *$ & $-.70^{* *}$ & $-.66^{* *}$ & $-.69 * *$ & - & \\
\hline 22 Cluster 3 (Aggressives) & 0.18 & 0.39 & .04 & $.33 * *$ & $.17 * *$ & $.31^{* *}$ & $.65^{* *}$ & $.64^{* *}$ & $.61^{* *}$ & $.64 * *$ & $.62 * *$ & $.59 * *$ & $.46^{* *}$ & $.48^{* *}$ & $.47 * *$ & $.39 * *$ & $.33^{* *}$ & $.32 * *$ & $.38^{* *}$ & $.23 * *$ & $.23 * *$ & $-.38 * *$ & $-.41 * *$ & - \\
\hline
\end{tabular}




\section{Table 6}

Summary of Discriminant Analysis for Study 3

\begin{tabular}{|c|c|c|}
\hline Variables and Parameters & \multirow{2}{*}{$\frac{\text { Sample } 1 \text { (w/o controls) }}{309}$} & \multirow{2}{*}{$\frac{\text { Sample } 1(\mathrm{w} / \text { controls }}{306}$} \\
\hline$N$ & & \\
\hline \multicolumn{3}{|l|}{ Passives } \\
\hline Number of Cases & 132 & 130 \\
\hline Political Skill $M$ & 5.14 & 5.14 \\
\hline Political Skill SD & 0.81 & 0.82 \\
\hline Political Will $M$ & 2.97 & 2.98 \\
\hline Political Will SD & 1.14 & 1.13 \\
\hline Self-Monitoring $M$ & & 2.74 \\
\hline Self-Monitoring $S D$ & & 0.43 \\
\hline Machiavellianism $M$ & & 2.49 \\
\hline Machiavellianism $S D$ & & 0.37 \\
\hline \multicolumn{3}{|l|}{ Aggressives } \\
\hline Number of Cases & 57 & 56 \\
\hline Political Skill $M$ & 5.43 & 5.40 \\
\hline Political Skill SD & 0.88 & 0.87 \\
\hline Political Will $M$ & 4.42 & 4.40 \\
\hline Political Will SD & 1.20 & 1.19 \\
\hline Self-Monitoring $M$ & & 3.07 \\
\hline Self-Monitoring $S D$ & & 0.31 \\
\hline Machiavellianism $M$ & & 2.84 \\
\hline Machiavellianism $S D$ & & 0.32 \\
\hline \multicolumn{3}{|l|}{ Positives } \\
\hline Number of Cases & 120 & 120 \\
\hline Political Skill M & 5.62 & 5.62 \\
\hline Political Skill SD & 0.71 & 0.71 \\
\hline Political Will $M$ & 3.83 & 3.83 \\
\hline Political Will SD & 0.98 & 0.98 \\
\hline Self-Monitoring $M$ & & 3.07 \\
\hline Self-Monitoring $S D$ & & 0.44 \\
\hline Machiavellianism $M$ & & 2.64 \\
\hline Machiavellianism $S D$ & & 0.35 \\
\hline \multirow{2}{*}{$\begin{array}{l}\text { Wilks Lambda - Function } 1 \text { - } 2 \\
p \text {-value }\end{array}$} & 0.75 & 0.67 \\
\hline & $<.001$ & $<.001$ \\
\hline Wilks Lambda - Function 2 & 0.97 & 0.96 \\
\hline$p$-value & $<.01$ & $<.01$ \\
\hline \multirow{2}{*}{ Squared Canonical Correlation - Function 1} & 0.22 & 0.30 \\
\hline & 0.03 & 0.04 \\
\hline
\end{tabular}




\section{Table 7}

Standardized Canonical Discriminant Function Coefficients and Structure Matrices

Study 3 (w/o controls)

Standardized Canonical Discriminant Function

$\begin{array}{lcc}\text { Variable } & \text { Function } 1 & \text { Function } 2 \\ \text { Political Skill } & 0.32 & 0.96 \\ \text { Political Will } & 0.91 & -0.43\end{array}$

Structure Matrix

\begin{tabular}{lccc} 
Variable & & Function 1 & Function 2 \\
\cline { 1 - 1 } Political Skill & & 0.43 & 0.91 \\
Political Will & & 0.95 & -0.31
\end{tabular}

Study 3 (w/ controls)

Standardized Canonical Discriminant Function

$\begin{array}{lcc}\text { Variable } & \text { Function } 1 & \text { Function } \\ \text { Political Skill } & 0.35 & 0.54 \\ \text { Political Will } & 0.60 & -0.33 \\ \text { Self-Monitoring } & 0.33 & 0.5 \\ \text { Machiavellianism } & 0.45 & -0.44\end{array}$

Structure Matrix

\begin{tabular}{lccc} 
Variable & & Function 1 & Function 2 \\
\cline { 1 - 1 } Political Skill & & 0.35 & 0.76 \\
Political Will & & 0.76 & -0.28 \\
Self-Monitoring & & 0.58 & 0.49 \\
Machiavellianism & & 0.51 & -0.58
\end{tabular}

